\title{
Complex aortic surgery in a regional center in the United Kingdom. Should the United Kingdom now adopt a United States-style supercenter model?
}

Priyadharshanan Ariyaratnam, BM, BSc (Hons), MRCS, Mahmoud Loubani, MD, FRCS (CTh), FECTS, Steven C. Griffin, FRCS (CTh), Michael E. Cowen, FRCS (CTh), Ajith Vijayan, FRCA, Martin A. Jarvis, FRCS (CTh), and Alexander R. J. Cale, FRCS (CTh)

\begin{abstract}
Background: The United States has established aortic supercenters, which have demonstrated clear improvements in the short-term and long-term outcomes after surgery on the thoracic aorta. This model of care does not exist in the United Kingdom. We have looked at our recent experience of emergency and elective thoracic aortic surgery and describe and compare our operative outcomes and 10-year survival with other regional centers and supercenters worldwide.
\end{abstract}

\begin{abstract}
Methods: This was a retrospective analysis of data collected prospectively from our cardiac database on patients who underwent surgery on the thoracic aorta $(\mathrm{n}=318)$ between November 1999 and November 2012. The outcome measures were adjusted operative mortality, postoperative complications, and long-term survival.

Results: Type A dissection was carried out on $23.90 \%$ of the patients and $76.10 \%$ had surgery on the aortic root and thoracic aorta for nondissection. The mean age of the patients was $62.21 \pm 14.1$ years. The mean logistic EuroSCORE was 26 in the dissection group and 19 in the nondissection group. Hospital mortality was significantly greater $(P<.05)$ in the dissection group compared with the nondissection group $(23.7 \%$ vs $12.8 \%)$. Survival after dissection and nondissection surgery was $66.3 \% \pm 5.6 \%$ versus $77.4 \% \pm 2.8 \%$, respectively, at 3 years, $63.9 \% \pm 5.9 \%$ versus $71.8 \% \pm 3.2 \%$ at 5 years, and $53.7 \% \pm 7.4 \%$ versus $47.1 \% \pm 6.0 \%$ at 10 years.
\end{abstract}

Conclusions: Our outcomes are comparable with other regional centers worldwide; however, they are not as good as those reported from the aortic supercenters. There should be continued impetus regarding the establishment of thoracic aortic surgery guidelines and specialist aortic centers in the United Kingdom. (J Thorac Cardiovasc Surg 2014;148:1428-34)

Supplemental material is available online.

Operations on the aortic root and ascending aorta are challenging operations for the whole cardiothoracic surgical team. Morbidity and mortality after these operations are still significant across the developed world, especially in the case of emergency surgery for type A aortic dissection. ${ }^{1,2}$

Although procedures such as valve-sparing aortic root replacement have gained significant popularity in recent years, the learning curve for these technically demanding procedures is still a deterrent to universal adoption.,

The Society of Thoracic Surgeons Clinical Practice Guidelines for the management of aortic valve disease

From the Department of Cardiothoracic Surgery, Castle Hill Hospital, Cottingham, United Kingdom.

Disclosures: Authors have nothing to disclose with regard to commercial support. Received for publication Oct 28, 2013; revisions received Dec 14, 2013; accepted for publication Jan 10, 2014; available ahead of print Feb 9, 2014.

Address for reprints: Priyadharshanan Ariyaratnam, BM, BSc (Hons), MRCS, Department of Cardiothoracic Surgery, Castle Hill Hospital, Cottingham, HU16 5JQ, United Kingdom (E-mail: priyadariyaratnam@yahoo.co.uk).

0022-5223/\$36.00

Copyright (c) 2014 by The American Association for Thoracic Surgery

http://dx.doi.org/10.1016/j.jtcvs.2014.01.009 and ascending aorta disease is to be commended for providing a framework to plan and manage this entity in North America, drawing on the specialized experience of the leading experts within the field. Unfortunately, there is still a significant lag for a UK consensus on how best to manage thoracic aortic disease. ${ }^{5}$

The in-hospital survival and long-term survival for thoracic aortic surgery in the United States is very impressive in specialized high-volume centers compared with lowvolume centers. ${ }^{6}$ The idea of such supercenters for aortic surgery has been floated in the United Kingdom so that the highest quality of preoperative evaluation, operative management, and follow-up can be provided for these patients.

We look at our recent experience over the last 12 years of practicing elective and emergency thoracic aortic surgery at our regional unit including patient demographics, inhospital results such as mortality and postoperative outcomes, as well as 10-year survival.

\section{METHODS \\ Design \\ Approval for this study was obtained from our Institutional Review Board. We performed a retrospective analysis of data gathered contempo- raneously in our departmental database and supplemented from the records}




\section{Abbreviations and Acronyms \\ $\mathrm{CT}=$ computed tomography \\ Log ES = logistic EuroSCORE \\ SCTS = Society for Cardiothoracic Surgery in Great Britain \& Ireland \\ STS $=$ Society of Thoracic Surgeons}

of patients undergoing emergency or elective surgery on the ascending aorta and aortic root between November 1999 and November 2012. We identified 318 consecutive patients.

The preoperative and intraoperative characteristics of all patients were examined. In-hospital postoperative outcomes, including mortality, renal, neurologic, gastrointestinal, respiratory, cardiovascular, and wound complications, were evaluated. Operative mortality was defined as death occurring during the operative hospitalization or within 30 days of operation for discharged patients. The preoperative characteristics were as defined by the EuroSCORE I criteria.

\section{Operative Technique}

Exposure was obtained by median sternotomy. Cannulation was performed after systemic heparinization. Central cannulation was obtained wherever possible except in redo surgery for which femoral cannulation was obtained before opening the chest. After the institution of cardiopulmonary bypass, patients who required deep hypothermic circulatory arrest were cooled to a rectal temperature of $17^{\circ} \mathrm{C}$. The remaining patients were cooled to $28^{\circ} \mathrm{C}$. The ascending aorta was clamped and the proximal repair was accomplished during cooling. Cold blood cardioplegic solution, administered antegrade and retrograde, was used for myocardial protection. Gelatin-coated Dacron grafts were used for aortic segment replacement. Bileaflet mechanical valves were used in the course of aortic root replacement for patients younger than 60 years of age and bioprosthetic valves were used in patients older than 60 years of age. Composite valve-graft conduits were used in the case of aortic root replacement. Teflon felt was used to reinforce graft-to-aorta anastomosis. Concomitant coronary artery bypass grafting was accomplished using saphenous vein grafts.

\section{Monitoring Patients}

Patients were followed up routinely at the clinic 8 weeks after their operation. Follow-up was $100 \%$ complete during a 6-month closing interval ending January 2013.

Long-term survival data were obtained from the national online $\mathrm{Na}$ tional Health Service registry. Long-term survival data included death from all causes.

All patients were followed up for life, if possible, at our regional center. All patients had a yearly computed tomography (CT) scan at our institution for the first 2 years. If there was no evidence of disease progression, then this was extended to follow-up every 2 years. If patients developed renal disease, CT scans were replaced with magnetic resonance imaging scans. Echocardiograms were not routinely used in follow-up unless there was a clinical indication on history and examination. Patients with mechanical valves were prescribed warfarin. Blood pressure was managed postoperatively with $\beta$-blockers and/or angiotensin-converting enzyme inhibitors initially unless contraindicated. The family practitioner then managed the patient's pharmacologic blood pressure control aiming to keep systolic blood pressure less than $140 \mathrm{~mm} \mathrm{Hg}$ and diastolic blood pressure less than $80 \mathrm{~mm} \mathrm{Hg}$.

\section{Statistical Analysis}

Continuous variables were expressed as means \pm 1 standard deviation and categorical variables were expressed as percentages.
All variables were first analyzed with univariate analysis $\left(\chi^{2}\right.$, MannWhitney, Kruskal-Wallis, or analysis of variance depending on the scale of measurement of the variables) to determine whether any single factor influenced mortality. Variables that achieved a $P$ value of less than .05 in the univariate analysis were examined with multivariate Cox proportional hazard analysis to evaluate independent risk factors for mortality (SPSS version 19.0 software; SPSS, Inc, Chicago, Ill). A Hosmer-Lemeshow test was the preferred test of goodness-of-fit.

\section{RESULTS}

\section{Preoperative and Operative Characteristics}

Seventy-six of the 318 patients $(23.90 \%)$ had surgery for type A dissection, whereas $76.10 \%(242 / 318)$ had surgery on the aortic root and thoracic aorta for nondissection.

The preoperative characteristics for the patients in the dissection and nondissection groups are shown in Table 1.

The patients in the dissection and nondissection groups were comparable for most preoperative factors including age, gender, New York Heart Association status, and comorbidities such as chronic obstructive pulmonary disease, peripheral vascular disease, and preoperative atrial fibrillation $(P>.05)$. However, the patients in the dissection group had significantly $(P<.05)$ higher mean logistic EuroSCORE and a higher incidence of preoperative renal failure. From our dissection cohort, 47 of 76 patients had hypertension. The mean age of these patients was 65.56 years. The mean age was of the remaining nonhypertensive patients was 54.31 years, and this was significantly different $(P=.000244)$.

Table 2 shows the intraoperative and postoperative characteristics of the patient cohort in the dissection and nondissection groups. Both groups had comparable intraoperative bypass and crossclamp times with similar blood loss and blood product delivery $(P>.05)$.

Within the dissection group of 76 patients, 38 patients had an interposition graft only, 7 patients had an extended hemi-arch replacement, 23 patients had an aortic root replacement (composite valve and conduit), 7 patients had resuspension of their aortic valve, and 1 patient had an interposition graft and aortic valve replacement separately.

Table 3 demonstrates that most of the operations in the nondissection group consisted of combined ascending aorta and aortic valve replacements without repair of the aortic root $(53.7 \%)$. Although aortic root replacement was performed in $7.4 \%$ of the patients, less than half of these $(3.3 \%)$ were valve-sparing procedures; the remainder were composite valve and root conduits. Arch replacement occurred in $2.9 \%$ of patients.

\section{In-Hospital Postoperative Outcomes}

Table 2 also demonstrates that in-hospital mortality, postoperative renal failure, postoperative neurologic complications, and the incidence of ischemic bowel were significantly greater in the dissection group $(P<.05)$. 
TABLE 1. Comparison of preoperative characteristics between the dissection and nondissection groups

\begin{tabular}{|c|c|c|c|c|c|}
\hline & \multicolumn{2}{|c|}{ Dissection } & \multicolumn{2}{|c|}{ Nondissection } & \multirow[b]{2}{*}{$P$ value } \\
\hline & Mean or $\%$ & $\begin{array}{c}\text { Standard } \\
\text { deviation or proportion }\end{array}$ & Mean or $\%$ & $\begin{array}{c}\text { Standard } \\
\text { deviation or proportion }\end{array}$ & \\
\hline Mean age at surgery (y) & 61.12 & 13.840 & 62.21 & 14.052 & .55 \\
\hline Mean body mass index & 26.9646 & 4.24121 & 27.682 & 4.8997 & .25 \\
\hline Mean logistic EuroSCORE & 26.1162 & 20.11063 & 19.33 & 38.855 & .00 \\
\hline$\%$ Male & 67.1 & $51 / 76$ & 60.3 & $146 / 242$ & .35 \\
\hline$\%$ NHYA class IV & 13.2 & $10 / 76$ & 17.8 & $43 / 242$ & .33 \\
\hline$\%$ COPD & 18.4 & $14 / 76$ & 17.4 & $42 / 242$ & .87 \\
\hline Previous myocardial infarction $(\%)$ & 18.4 & $14 / 76$ & 9.9 & $24 / 242$ & .51 \\
\hline Previous cardiac surgery $(\%)$ & 10.5 & $8 / 76$ & 16.9 & $41 / 242$ & .17 \\
\hline Hypertension (\%) & 61.8 & $47 / 76$ & 60.3 & $146 / 242$ & .91 \\
\hline Diabetes mellitus (non-diet controlled) $(\%)$ & 3.9 & $3 / 76$ & 5.4 & $13 / 242$ & .61 \\
\hline Renal failure (\%) & 10.5 & $8 / 76$ & 1.2 & $3 / 242$ & .00 \\
\hline Neurologic dysfunction/TIA (\%) & 9.2 & $7 / 76$ & 13.6 & $33 / 242$ & .30 \\
\hline Peripheral vascular disease $(\%)$ & 15.8 & $12 / 76$ & 14.9 & $36 / 242$ & .79 \\
\hline Preoperative arrhythmias (\%) & 10.5 & $8 / 76$ & 15.3 & $37 / 242$ & .28 \\
\hline Poor ejection fraction $(\%)$ & 2.6 & $2 / 76$ & 2.9 & $7 / 242$ & .89 \\
\hline Ventilated $(\%)$ & 3.9 & $3 / 76$ & 0 & 0 & .59 \\
\hline
\end{tabular}

NYHA, New York Heart Association; COPD, chronic obstructive pulmonary disease; TIA, transient ischemic attack.

The in-hospital mortality was $12.8 \%$ in the nondissection group. Of these deaths, $45.2 \%$ were caused by cardiac failure, $9.7 \%$ were caused by an intracerebral event, and $12.9 \%$ were caused by septicemia.

The in-hospital mortality was $23.7 \%$ in the dissection group. Of these deaths, $33 \%$ were caused by cardiac failure and $5.6 \%$ were caused by an intracerebral event.

Table E1 (Online Data Supplement) shows the results of the logistic regression analysis for predictors of higher hospital mortality in both the nondissection and dissection groups. The result of the Hosmer-Lemeshow test was 0.782 and 0.404 for the nondissection and dissection groups, respectively, indicating that our model was a good fit.

Multivariate analysis revealed that hypertension and peripheral vascular disease were significant predictors of inhospital mortality in the dissection group $(P<.05)$.

Multivariate analysis revealed that previous cardiac surgery and a prolonged crossclamp time were significant

TABLE 2. Comparison of the operative and postoperative characteristics of the patients in the dissection and nondissection groups

\begin{tabular}{|c|c|c|c|c|c|}
\hline & \multicolumn{2}{|r|}{ Dissection } & \multicolumn{2}{|c|}{ Nondissection } & \multirow[b]{2}{*}{$P$ value } \\
\hline & Mean or $\%$ & $\begin{array}{c}\text { Standard } \\
\text { deviation or proportion }\end{array}$ & Mean or $\%$ & $\begin{array}{c}\text { Standard } \\
\text { deviation or proportion }\end{array}$ & \\
\hline Intra-aortic balloon pump intra-/postoperatively ( $\%$ ) & 46.1 & $35 / 76$ & 50 & $121 / 242$ & .565 \\
\hline Mean cumulative crossclamp time (min) & 82.13 & 36.991 & 83.02 & 32.343 & .843 \\
\hline Mean cumulative bypass time (min) & 146.57 & 59.640 & 138.99 & 58.046 & .327 \\
\hline Mean lowest core temperature $\left({ }^{\circ} \mathrm{C}\right)$ & 20.915 & 6.1270 & 25.34 & 7.089 & .00 \\
\hline Mean total packed cells used (mL) & 874.44 & 1002.583 & 690.96 & 1288.223 & .270 \\
\hline Mean total FFP used (mL) & 510.19 & 773.303 & 384.56 & 925.992 & .300 \\
\hline Mean total platelets used (mL) & 294.82 & 472.697 & 189.74 & 399.369 & .064 \\
\hline Mean total blood loss (mL) & 1024.18 & 1116.267 & 883.33 & 1369.000 & .433 \\
\hline Reopening for bleeding/tamponade $(\%)$ & 11.8 & $9 / 76$ & 13.6 & $33 / 242$ & .270 \\
\hline Postoperative arrhythmia (\%) & 55.3 & $42 / 76$ & 57.9 & $140 / 242$ & .612 \\
\hline Low cardiac output (requiring inotropes) $(\%)$ & 84.2 & $64 / 76$ & 64.9 & $157 / 242$ & .02 \\
\hline Pulmonary complications $(\%)$ & 43.4 & $33 / 76$ & 38.4 & $93 / 242$ & .486 \\
\hline Wound infection (superficial and deep) $(\%)$ & 13.2 & $10 / 76$ & 16.9 & $41 / 242$ & .412 \\
\hline Renal failure $(\%)$ & 30.3 & $23 / 76$ & 15.3 & $37 / 242$ & .004 \\
\hline Ischemic bowel (\%) & 2.63 & $2 / 76$ & 0 & 0 & .002 \\
\hline Residual neurologic deficit $(\%)$ & 10.52 & $8 / 76$ & 4.96 & $12 / 242$ & .00 \\
\hline Mean no. of $d$ in ICU & 5.06 & 6.055 & 4.11 & 9.52 & .412 \\
\hline Mean total stay (d) & 16.86 & 16.401 & 14.3201 & 13.89465 & .590 \\
\hline In-hospital mortality $(\%)$ & 23.7 & & 12.8 & & .025 \\
\hline
\end{tabular}

FFP, Fresh frozen plasma; $I C U$, intensive care unit. 
TABLE 3. Pathologies and procedures associated with the nondissection group

\begin{tabular}{lrr}
\hline & Pathology or operation performed & Proportion \\
\hline Marfan disease & $9 / 242$ & 3.71 \\
Ascending aorta replacement and valve replacement & 53.7 & 22.3 \\
Ascending aorta replacement only (for ascending aorta aneurysms) & 9.9 \\
Aortic valve replacement and aortic root enlargement & $54 / 242$ & $7.4(3.31)$ \\
Aortic root replacement (valve sparing) for aortic root aneurysms & 4.1 \\
Aortic root and ascending aorta replacement for aortic root and ascending aortic aneurysms & 13.1 \\
Concomitant coronary artery bypass grafting & $18 / 242(8 / 242)$ \\
Arch replacement & $10 / 242$ \\
Debranching of aortic arch & $39 / 242$ & 2.9 \\
\hline
\end{tabular}

predictors of in-hospital mortality in the nondissection group $(P<.05)$.

Within the nondissection group, patients undergoing root surgery had a significantly higher mortality compared with those patients having surgery on the ascending aorta alone $(P<.05)$.

\section{Survival}

Dissection surgery. The 3-year, 5-year and 10-year survival for dissections was $66.3 \% \pm 5.6 \%, 63.9 \% \pm 5.9 \%$, and $53.7 \% \pm 7.4 \%$, respectively. Figure 1 shows the Kaplan-Meier survival graph for dissection surgery. Cox regression analysis showed that previous cardiac surgery was a significant predictor of long-term survival in the dissection group.

Nondissection surgery. The 3-year, 5-year, and 10-year survival for nondissections was $77.4 \% \pm 2.8 \%, 71.8 \% \pm$ $3.2 \%$, and $47.1 \% \pm 6.0 \%$, respectively. Figure $2, A$ shows the Kaplan-Meier survival graph for all nondissection surgery on the thoracic aorta. Figure 2, $B$ shows the Kaplan-Meier survival graph for all nondissection surgery on the thoracic aorta stratified to specific procedures. Log-rank analysis revealed that there was no difference in survival between operating on the ascending aorta alone or concomitant aortic root/ aortic valve surgery $(P=.190)$. Cox regression analysis revealed the hypertension and poor ejection fraction were significant predictors of long-term mortality after nondissection surgery $(P<.05)$ (Table E2 in the Online Data Supplement).

\section{Reoperations}

With regard to reoperations, 3 people had reoperations after their original thoracic aorta surgery. One patient had a type A aortic dissection repair 2 years and 4 months after replacement of the aortic root. One patient had a replacement of the descending thoracic aorta 1 month after repair of a type A dissection. One patient had a replacement of the aortic root 9 years and 11 months after an aortic valve replacement and root enlargement.

\section{DISCUSSION}

Although there have been suggestions that thoracic aortic surgery should be performed in specialist centers in the
United Kingdom, it is still largely performed in regional cardiothoracic centers with no fervent desire to establish clear leadership in this field. This contrasts with the position in North America, where it is recognized that specialist aortic supercenters provide the best management pathways for these patients. ${ }^{7}$ Our results illustrate what can be achieved in this current regional arrangement, and these data need to be compared with what is achieved elsewhere.

\section{Dissection Surgery}

In-hospital mortality in other UK regional centers, international regional centers, and supercenters. Within our own patient subgroup, in-hospital observed mortality compares with predicted mortality as calculated using logistic EuroSCORE (Log ES). The mean Log ES predicted risk of death for the acute type A dissection group was $26.1 \%$. The actual observed in-hospital mortality was $23.7 \%$. Log ES was used as opposed to the Society of Thoracic Surgeons (STS) scoring system because within the United Kingdom, the national cardiac surgery database includes factors relating to the Log ES; there are factors that the STS has that we do not routinely incorporate. One may

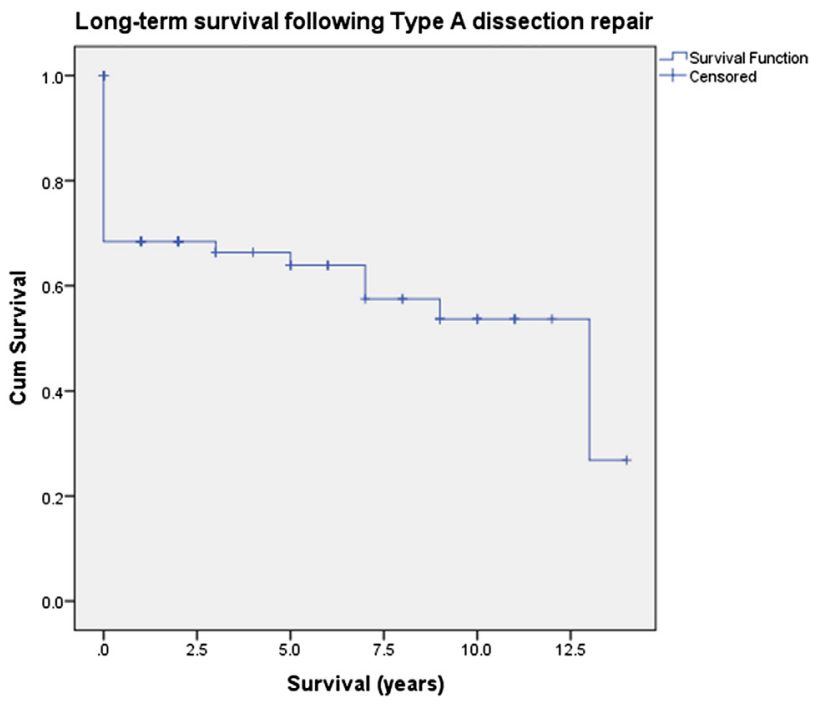

FIGURE 1. Kaplan-Meier survival curve for dissection surgery. 

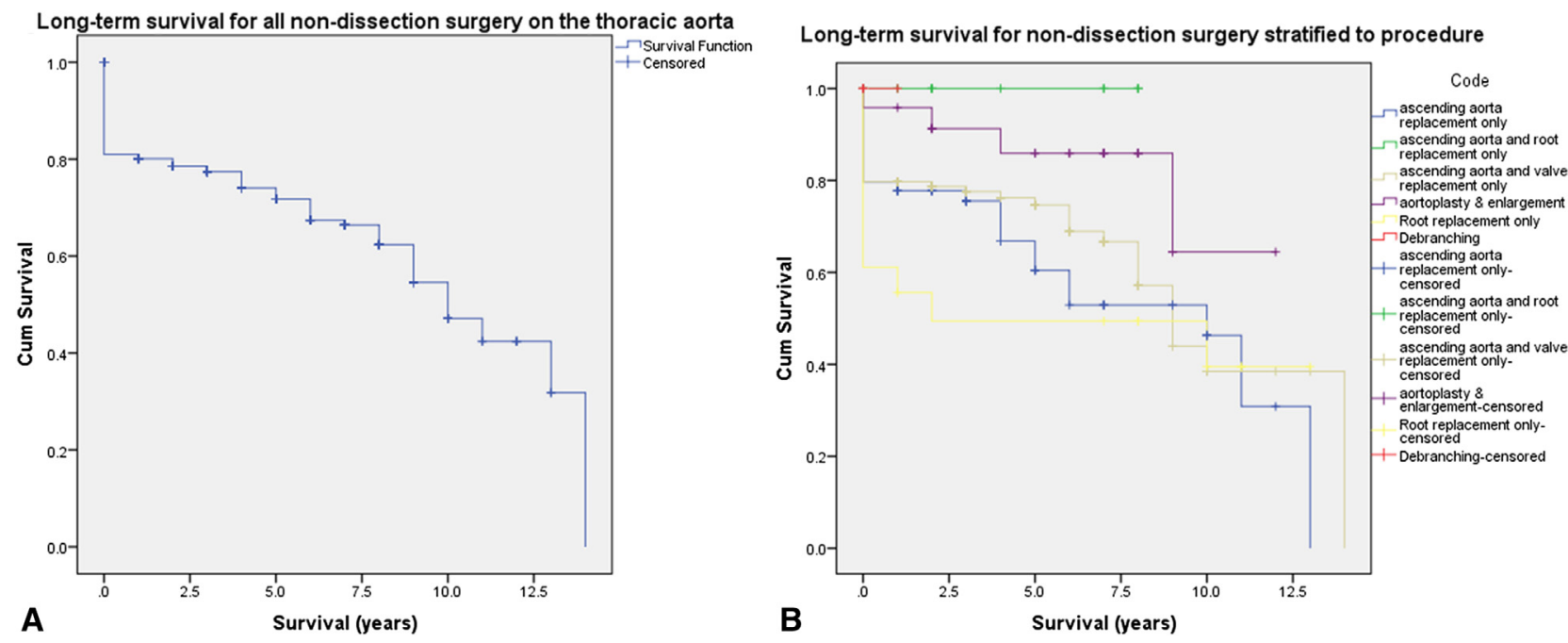

FIGURE 2. A, Kaplan-Meier survival curve for all nondissection surgery. B, Kaplan-Meier survival curve for nondissection surgery stratified according to procedure.

argue that the Log ES is not always as an accurate predictor of more complex surgery but this may only add weight to the fact that aortic surgery must be treated as a unique entity within the specialty.

These observed in-hospital mortality results compare favorably with other regional centers in the United Kingdom. The Society for Cardiothoracic Surgery in Great Britain \& Ireland (SCTS) published the results of aortic surgery in the United Kingdom in $2008 .{ }^{8}$ They showed that for all the centers included in the report, the overall mortality for dissection repair was $22.8 \%$.

In Europe and the wider world, mortality for operated type A dissection ranges from $19 \%$ to $42 \%{ }^{9,10}$ Preoperative factors such as an older age and diabetes were found to be significant independent predictors of mortality; postoperative complications such as renal failure and mesenteric ischemia were also important in determining in-hospital mortality. What these studies and our study illustrate is that not all the factors in the EuroSCORE I that determine mortality in cardiac surgery in general play such a conclusive role in surgery on the thoracic aorta.

Specialist (super) centers, such as in Pennsylvania, have developed their own unique risk stratification scoring system for aortic surgery: the Penn Classification. This system differs from the traditional scoring system by including preoperative ischemia pattern within risk analysis by stratifying patients as having no ischemia, branch vessel malperfusion with localized organ ischemia, generalized ischemia with circulatory collapse, with or without cardiac involvement, or a combination of localized and generalized ischemia. ${ }^{11}$ Such an example demonstrates why aortic surgery must be considered as a unique entity to be managed by specialist protocols rather than on generalized cardiothoracic principles and risk stratification systems.

In these supercenters, the mortality is incredibly low. Geirsson and colleagues ${ }^{12}$ report an in-hospital mortality of $12.7 \%$. This is not unique as the mortality in other supercenters such as the Texas Heart Institute are also very impressive at $12 \%$ to $13.8 \%{ }^{13}$

Long-term mortality in other UK regional centers, international regional centers, and supercenters. The SCTS have not yet published data on long-term survival after dissection repair. Our report is one of the few to document this in the United Kingdom.

Regarding long-term survival, our 10-year survival after surgery for acute type A dissection is comparable with other European regional centers where 10 -year survival ranges from $40 \%$ to $60 \%$. ${ }^{14,15}$

Compared with regional centers in the United States, our results for are comparable for patients in the same age group. For example, the 10-year survival in patients with an average age of 62 years undergoing surgery for type A dissections was around $55 \%{ }^{16}$

Early survival for patients treated in aortic supercenters is better. For example, an analysis of 8 tertiary referral centers in the United States with a specialist interest in thoracic aortic surgery revealed that the 3-year survival was $90 \%$ compared with $66 \%$ at our center. ${ }^{17}$

\section{Nondissection Surgery}

In-hospital mortality in other UK regional centers, international regional centers, and supercenters. The mean Log ES predicted risk of death was $19.3 \%$ in the nondissection group. Our actual observed in-hospital mortality was lower at $12.8 \%$.

The SCTS database reports that the average in-hospital mortality for all elective surgery on the thoracic aorta is $12.9 \%$ based on 5222 cases between 2004 and 2008. ${ }^{8}$ Patients having an interposition graft only had a higher mortality than those having an interposition graft and aortic valve replacement and those having a composite valve graft $(15.1 \%, 10.5 \%$, and $13.7 \%$, respectively). 
Outside the United Kingdom, in-hospital mortality from elective surgery on the thoracic aorta ranges from $5 \%$ to $10 \%$ in regional centers. ${ }^{18,19}$

High-volume (super) centers had lower hospital mortality (as low as $3.7 \%$ in some centers) in addition to lower postoperative morbidity for thoracic aneurysm repairs compared with low-volume centers not only in the United States but across the world..$^{20,21}$

Long-term mortality in other UK regional centers, international regional centers, and supercenters. Long-term data for elective operations on the thoracic aorta are more difficult to find in Europe. Overall survival for all types of ascending thoracic aortic surgery ranges from 54\% to $60 \%$ at 10 years but is slightly better on Kaplan-Meier graphs if the operations are stratified according to urgency. ${ }^{22,23}$

The influence of certain factors such as redo surgery greatly reduces these figures for elective operations on the thoracic aorta. For example, 10 -year survival is as low as $45 \%$ in these patients. ${ }^{24}$ This is supported by our data; previous cardiac surgery is an important predictor of poor long-term survival.

The factors that determine in-hospital mortality do not necessarily determine long-term outcomes. ${ }^{18}$ Hence, this outlines the importance of persevering with obtaining long-term outcomes in aortic surgery to better understand which factors can be addressed to improve survival.

The slightly lower 10-year survival results from our patient population may be accounted for by the mean age of 62 years in our patient cohort, which is at the higher end of the spectrum compared with other reported outcome data. In addition, advanced age at the time of the operation may play a role in the varying long-term survival. ${ }^{25}$

Nondissection surgery in high-volume (super) centers in North America show that the 10-year survival is more than $70 \%$ for ascending aorta replacement ${ }^{26}$ and more than $79 \%$ for aortic root aneurysm repair using valve-sparing and composite valve-conduit techniques. ${ }^{27,28}$ This may reflect improved diagnostic imaging and patient selection, operative technique and operative volume, and specialized postoperative management, all of which are factors that vary greatly between high-volume centers and regional centers. ${ }^{6,29}$

Case mix of our population compared with other centers. The intraoperative characteristics of the dissection and nondissection groups were similar with regard to operating time, the use of hypothermia, and blood loss. Our results clearly show that patients undergoing acute type A dissection do worse than patients having elective surgery in the short term with regard to in-hospital mortality, renal complications, and gastrointestinal complications. This is established in other studies. However, our results also show that patients undergoing dissection do not fare worse in the longer term with comparable 5- and 10-year survival.
Our data on elective cases demonstrate that there is no significant difference in mortality between procedures whether they are operations on the ascending aorta or aortic root alone or operations on the ascending aorta in concert with aortic valve replacement or aortic root. This has been observed previously, ${ }^{30}$ but other studies have shown the contrary. For example, those patients undergoing supracoronary replacement of the ascending aorta with separate aortic valve replacement have been shown do worse in the longer term than those who have a composite operation such as a Bentall procedure. ${ }^{31}$ It remains uncertain whether this is due to the operation or the primary pathology.

Very few of our aortic root operations included valvesparing techniques such as remodeling of the aortic root or reimplantation of the aortic valve as espoused by David and colleagues. ${ }^{3}$ It is unclear why this is but the reason may include reluctance to experiment on a learning curve of a technically demanding technique when a more established method of composite valve-conduit replacement would be more in keeping with the general cardiothoracic surgeon's comfort zone.

One may argue from our results that we have a focused group. All the patients in the dissection group underwent acute type A aortic dissection with no chronic dissections. Only 10 patients had some procedure on the aortic arch and none on the descending thoracic or thoracoabdominal aorta. In many ways, it could be these the procedures performed on our patients do not make for a more convincing argument for aortic supercenters. However, our task is to establish whether the surgery that we are currently conducting should be conducted in specialist centers.

\section{The Need for Supercenters in the United Kingdom?}

Hitherto, few studies in the United Kingdom have looked at the regional center experience of thoracic aortic surgery. Our study provides an important contribution on the shortterm and long-term outcomes after elective and emergency surgery on the thoracic aorta in the United Kingdom.

We believe that our results are comparable with other regional centers across the world. Although this is reassuring, it provides food for thought as to whether the United Kingdom should move on to the option of establishing national aortic guidelines and centers. Such centers would allow those surgeons talented in this field to provide a focused level of care within the context of a specialized multidisciplinary team, drive down in-hospital mortality and morbidity, and drive up long-term survival. It would further allow the trainees of the future to enter those steep learning curves attributed to complex techniques such as aortic root remodeling and aortic valve reimplantation that some general cardiothoracic surgeons in regional centers may shy away from.

There have been notable examples of prominent aortic surgeons in the United Kingdom, such as the late Robert Bonser, $^{7}$ however the notion of concentrating surgeons 
who excel in this field is still in its infancy. The United Kingdom is experimenting with this at the moment in centers such as Liverpool, which has a dedicated multidisciplinary aortic surgery service, although the short-term and long-term results of this venture are pending.

Setting up a supercenter is difficult in terms of finance and logistics. Inevitably, resources and staff may need to be centralized from peripheral regional centers and this will take time. The flip side of the coin may be with regard to follow-up. We have good follow-up in our unit as patients are relatively local. When supercenters come into play, follow-up would be difficult to achieve and this may need to be devolved to regional cardiothoracic/vascular centers.

\section{CONCLUSIONS}

Our study demonstrates that regional centers performing aortic surgery, such as ours, have similar in-hospital mortality rates in the United Kingdom and the western world. Our study makes an important contribution to the data concerning long-term survival after aortic surgery; such data are lacking not only in the United Kingdom but across regional centers in the western world. We have shown that factors determining in-hospital mortality are not necessarily related to those factors governing long-term survival. We have shown that regional centers such as ours, do not have comparable outcomes with the supercenters that exist in the United States, particularly in the case of in-hospital mortality.

We would like to thank Neil Richards who is the audit manager for the cardiac surgical database at Castle Hill Hospital.

\section{References}

1. Wong DR, Lemaire SA, Coselli JS. Managing dissections of the thoracic aorta. Am Surg. 2008;74:364-80.

2. Trimarchi S, Eagle KA, Nienaber CA, Rampoldi V, Jonker FH, De Vincentiis C, et al; International Registry of Acute Aortic Dissection Investigators. Role of age in acute type A aortic dissection outcome: report from the International Registry of Acute Aortic Dissection (IRAD). J Thorac Cardiovasc Surg. 2010;140:784-9.

3. David TE, Maganti M, Armstrong S. Aortic root aneurysm: principles of repair and long-term follow-up. J Thorac Cardiovasc Surg. 2010;140(6 Suppl):S14-9.

4. Oka T, Okita Y, Matsumori M, Okada K, Minami H, Munakata H, et al. Aortic regurgitation after valve-sparing aortic root replacement: modes of failure. Ann Thorac Surg. 2011;92:1639-44.

5. Svensson LG, Adams DH, Bonow RO, Kouchoukos NT, Miller DC, O'Gara PT, et al. Aortic valve and ascending aorta guidelines for management and quality measures. Ann Thorac Surg. 2013;95(6 Suppl):S1-66.

6. Chikwe J, Cavallaro P, Itagaki S, Seigerman M, Diluozzo G, Adams DH. National outcomes in acute aortic dissection: influence of surgeon and institutional volume on operative mortality. Ann Thorac Surg. 2013;95:1563-9.

7. Czerny M, Bachet J, Bavaria J, Bonser RS, Borger MA, De Paulis R, et al. The future of aortic surgery in Europe. Eur J Cardiothorac Surg. 2013;43:226-30.

8. The Society for Cardiothoracic Surgery in Great Britain \& Ireland. Sixth National Audit Cardiac Surgical Database Report. 2008. Available at: http:// www.scts.org/_userfiles/resources/SixthNACSDreport2008withcovers.pdf. Accessed October 10, 2013

9. Kazui T, Washiyama N, Bashar AH, Terada H, Suzuki T, Ohkura K, et al. Surgical outcome of acute type A aortic dissection: analysis of risk factors. Ann Thorac Surg. 2002;74:75-81.

10. Pompilio G, Spirito R, Alamanni F, Agrifoglio M, Polvani G, Porqueddu M, et al. Determinants of early and late outcome after surgery for type A aortic dissection. World J Surg. 2001;25:1500-6.
11. Augoustides JG, Szeto WY, Desai ND, Pochettino A, Cheung AT, Savino JS, et al. Classification of acute type A dissection: focus on clinical presentation and extent. Eur J Cardiothorac Surg. 2011;39:519-22.

12. Geirsson A, Bavaria JE, Swarr D, Keane MG, Woo YJ, Szeto WY, et al. Fate of the residual distal and proximal aorta after acute type a dissection repair using a contemporary surgical reconstruction algorithm. Ann Thorac Surg. 2007;84: 1955-64.

13. Preventza O, Cervera R, Cooley DA, Bakaeen FG, Mohamed AS, Cheong BY, et al. Acute type I aortic dissection: traditional versus hybrid repair with antegrade stent delivery to the descending thoracic aorta. J Thorac Cardiovasc Surg. September 14, 2014 [Epub ahead of print].

14. Olsson C, Hillebrant CG, Liska J, Lockowandt U, Eriksson P, FrancoCereceda A. Mortality and reoperations in survivors operated on for acute type A aortic dissection and implications for catheter-based or hybrid interventions. J Vasc Surg. 2013;58:333-9.

15. Di Marco L, Pacini D, Leone A, Petridis FD, Bissoni L, Di Bartolomeo R, et al. Long-term outcome after acute type A aortic dissection: does an age limit still exist? J Cardiovasc Surg (Torino). May 28, 2012 [Epub ahead of print].

16. Stevens LM, Madsen JC, Isselbacher EM, Khairy P, MacGillivray TE, Hilgenberg AD, et al. Surgical management and long-term outcomes for acute ascending aortic dissection. J Thorac Cardiovasc Surg. 2009;138:1349-57.

17. Tsai TT, Evangelista A, Nienaber CA, Trimarchi S, Sechtem U, Fattori R, et al; International Registry of Acute Aortic Dissection (IRAD). Long-term survival in patients presenting with type A acute aortic dissection: insights from the International Registry of Acute Aortic Dissection (IRAD). Circulation. 2006; 114(1 Suppl):I350-6.

18. Biglioli P, Parolari A, Spirito R, Musumeci S, Agrifoglio M, Alamanni F, et al. Early and late results of ascending aorta surgery: risk factors for early and late outcome. World J Surg. 1997;21:590-8.

19. Dunne B, Marr T, Andrews D, Larbalestier R, Edwards M, Merry C. Aortic root replacement for ascending aortic disease: a 10 year review. Heart Lung Circ. 2012; http://dx.doi.org/10.1016/j.hlc.2012.08.050.

20. Gazoni LM, Speir AM, Kron IL, Fonner E, Crosby IK. Elective thoracic aortic aneurysm surgery: better outcomes from high-volume centers. J Am Coll Surg. 2010;210:855-9, 859-60.

21. Miyata H, Motomura N, Ueda Y, Tsukihara H, Tabayashi K, Takamoto S. Toward quality improvement of thoracic aortic surgery: estimating volume-outcome effect from nationwide survey. Eur J Cardiothorac Surg. 2009;36:517-21.

22. Olsson C, Thelin S, Ståhle E, Ekbom A, Granath F. Thoracic aortic aneurysm and dissection: increasing prevalence and improved outcomes reported in a nationwide population-based study of more than 14,000 cases from 1987 to 2002. Circulation. 2006;114:2611-8.

23. Bekkers JA, Te Riele RJ, Takkenberg JJ, Bol Raap G, Hofland J, RoosHesselink JW, et al. Thoracic aortic surgery: an overview of 40 years clinical practice. J Thorac Cardiovasc Surg. 2014;147:332-43.

24. Di Eusanio M, Berretta P, Bissoni L, Petridis FD, Di Marco L, Di Bartolomeo R. Re-operations on the proximal thoracic aorta: results and predictors of short- and long-term mortality in a series of 174 patients. Eur J Cardiothorac Surg. 2011; 40:1072-6.

25. Okita Y, Ando M, Minatoya K, Tagusari O, Kitamura S, Nakajjma N, et al. Early and long-term results of surgery for aneurysms of the thoracic aorta in septuagenarians and octogenarians. Eur J Cardiothorac Surg. 1999;16:317-23.

26. Estrera AL, Miller CC III, Huynh TT, Porat EE, Safi HJ. Replacement of the ascending and transverse aortic arch: determinants of long-term survival. Ann Thorac Surg. 2002;74:1058-64.

27. David TE, Feindel CM, Webb GD, Colman JM, Armstrong S, Maganti M. Longterm results of aortic valve-sparing operations for aortic root aneurysm. J Thorac Cardiovasc Surg. 2006;132:347-54

28. Zehr KJ, Orszulak TA, Mullany CJ, Matloobi A, Daly RC, Dearani JA, et al. Surgery for aneurysms of the aortic root: a 30-year experience. Circulation. 2004;110:1364-71.

29. Hughes GC, Zhao Y, Rankin JS, Scarborough JE, O'Brien S, Bavaria JE, et al. Effects of institutional volumes on operative outcomes for aortic root replacement in North America. J Thorac Cardiovasc Surg. 2013;145:166-70.

30. Kallenbach K, Kojic D, Oezsoez M, Bruckner T, Sandrio S, Arif R, et al. Treatment of ascending aortic aneurysms using different surgical techniques: a single-centre experience with 548 patients. Eur J Cardiothorac Surg. 2013; 44:337-45.

31. Sioris T, David TE, Ivanov J, Armstrong S, Feindel CM. Clinical outcomes after separate and composite replacement of the aortic valve and ascending aorta. J Thorac Cardiovasc Surg. 2004;128:260-5. 
TABLE E1. Multivariate logistic regression for in-hospital mortality

\begin{tabular}{|c|c|c|c|c|}
\hline & \multicolumn{2}{|c|}{ Dissection } & \multicolumn{2}{|c|}{ Nondissection } \\
\hline & $P$ value & Odds ratio & $P$ value & Odds ratio \\
\hline Older age & .200 & 8.101 & .279 & 0.451 \\
\hline Male & .103 & 0.299 & .165 & 1.982 \\
\hline NYHA class & .076 & 6.553 & .768 & 0.847 \\
\hline COPD & .078 & 5.007 & .322 & 1.732 \\
\hline Previous myocardial infarction & .138 & 4.559 & .313 & 1.998 \\
\hline Previous cardiac surgery & .806 & 0.676 & .006 & 4.026 \\
\hline Preoperative diabetes & .638 & 1.422 & .054 & 4.436 \\
\hline Hypertension & .027 & 9.325 & .086 & 2.335 \\
\hline Preoperative renal failure & .847 & 1.187 & .394 & 3.512 \\
\hline Peripheral vascular disease & .021 & 14.428 & .474 & 0.608 \\
\hline Poor ejection Fraction & .193 & 10.348 & .278 & 2.832 \\
\hline Cumulative bypass time & .259 & 0.312 & .917 & 0.946 \\
\hline Cumulative crossclamp time & .646 & 0.647 & .010 & 4.017 \\
\hline
\end{tabular}

NYHA, New York Heart Association; COPD, chronic obstructive pulmonary disease.

TABLE E2. Cox regression for long-term survival

\begin{tabular}{lcccc}
\hline & \multicolumn{2}{c}{ Dissection } & \multicolumn{2}{c}{ Nondissection } \\
\cline { 2 - 4 } & P value & Odds ratio & P value & .140 \\
Older age & .917 & 1.087 & .189 & 0.556 \\
Male & .230 & 0.608 & .104 & 0.726 \\
NYHA class & .667 & 1.254 & .332 & 1.591 \\
COPD & .055 & 2.587 & .297 & .065 \\
Previous cardiac surgery & .049 & 3.471 & .006 & 1.392 \\
Diabetes & .388 & 0.380 & .236 & 2.279 \\
Hypertension & .220 & 1.747 & .629 & 2.108 \\
Renal disease & .055 & 3.091 & .012 & 1.199 \\
Peripheral vascular disease & .768 & 0.854 & 1.252 & 3.575 \\
Ejection fraction & .836 & &
\end{tabular}

NYHA, New York Heart Association; COPD, chronic obstructive pulmonary disease. 